\title{
Training Teachers to Implement Evidence-Based Practices Specifically Designed for Students with Autism Spectrum Disorder
}

\author{
Ahmad Saad Alghamdi \\ University of South Florida, USA 4202 E Fowler Ave, Tampa, FL 33620 \\ Email address Saad6@usf.edu
}

\begin{abstract}
Special education teachers are usually subjected to in-service training on Evidence-Based Practices especially those who work with students Autism Spectrum Disorder (ASD). Increasing teacher's capability of using EBPs identified by the National Professional Development Center (NPDC) on ASD has become the most prominent need to serve students with autism. The purpose of this study was to investigate to what extent teachers' performance is related to EBPs when they after they start their career. A mixed methods research design used in this study to explore the most prevalent practices, the common type of training on these practices, and teachers' knowledge and perceptions of using these practices. The undergraduate preparation programs and modality of training and time consuming to achieve mastery level of implementation among teachers will be discussed. Ten teachers have participated in this study. Results indicated that most of the training programs left beginner teachers underprepared to implement EPBs for teaching students with autism.
\end{abstract}

Keywords: Evidence-based practice, Implementation, Teachers, Preparation, Training.

DOI: $10.7176 / \mathrm{JEP} / 12-17-02$

Publication date: June $30^{\text {th }} 2021$

\section{Introduction}

Although as movies help in bringing positive awareness on the subject of Autism Spectrum Disorder (ASD), they also make teachers assume that the children with the syndrome are skilled in different aspects of education. In reality, not all students with ASD are skilled learners. In fact, studies have indicated that during the middle school years, learners with the syndrome perform on average of five years below their peers who are neurotypical (Mohn, 2010). The Individuals with Disabilities Education Act 2004 (IDEA, 2004) describes ASD as a constructive defect that significantly affecting communication and social skills which negatively affects academic achievements for children.

What makes teachers struggle is that students with ASD show some repetitive events and repetitive movements that prevent students with ASD from concentrating on the learning process fully. There is also an unwillingness to change every day habitual activities or environmental change and abnormal actions to perceptive experiences. ASD is not applicable if a student's learning performance is negatively affected due to the experience of emotional disorder (American Psychiatric Association, 2013). Children with ASD have serious deficits in social skills, and they frequently lack the ability to carry out social interactions effectively (Meyer, Mundy, van Hecke \& Durocher, 2006). Their impaired communication style and inability to understand social cues will lead to adverse effects on social relationships and learning activities with their peers (Eaves \& Ho, 2008; Orsmond, Krauss \& Seltzer, 2004).

Researchers indicated there is a huge growth in the prevalence of this disability (Volkmar et al., 1997; Croen et al., 2000). Based on a survey was conducted by Disease Control and Prevention (CDC), the number of children classified as ASD in the U.S became 1 in 45 children (CDC, 2012), compared to a previous statistical report that showed that prevalence of autism in the U.S in 2008 was 1 in 88 children (CDC, 2012). Along with this increase in the U.S, there also a significant and fast increase in the number of enrollment in special education programs, however, teachers struggle to provide appropriate education programs due to their lack aware of based research interventions (Scull \& Winkler, 2011).

There is need for teachers who effectively implement learning practices specifically designed for children with autism. An evidence-based practice, therefore, can be defined as an instructional teaching program designed by teachers that has led to the achievement of positive results when experimentally tested on the students with disabilities (Mohn, 2010). Teachers should offer and implement a range of research-based educational instructional practices and service options for students with ASD. Therefore, a special educator requires the skill to access information regarding interventions and their relation to current promising practices in education.

\section{Rationale for study}

Special education teachers are usually subjected to in-service training on evidence-based practices especially those who work with Autism Spectrum Disorder (ASD). This type of training is to increasing teacher's 
capability of using EBPs identified by the National Professional Development Center (NPDC) on ASD became the most prominent need to serve students autism.

The Individuals with Disabilities Education Act 2004 (IDEA, 2004) describes ASD as a constructive defect significantly affecting oral and non-oral communication and social activities normally experienced prior to reaching three years of age, which negatively affect academic achievements for children. Subsequently teachers often struggle to provide appropriate education programs because they lack research-based interventions (Scull \& Winkler, 2011). The need to increase teachers' capability of using these strategies has become the most crucial requirement to serve students with autism. The evidence-based practice could be used to improve core, play, communication, or social skills that improves and facilitate the learning process. Special educators require the skills to access information regarding interventions and their relationship to current promising practices in education. The disadvantage in some teacher's preparation programs is the time required for one to use evidencebased practices. Teachers have to use what they have learned in their coursework preparation with students in the actual classroom immediately after the lessons, not after their graduation. The considerable number of evidencebased practices should be effectively implemented using proper strategies. These approaches will ensure that the students with ASD will not only improve their educational performance but will also improve in both the communication and social skills necessary for their learning development. When teachers are well-prepared on evidence-based practices they can ensure the best outcomes for students with ASD.

Not only will evidence-based practices help students academically, but also will improve their life skills and performance to a level that is the same as neurotypical students. More attention should be given to training and implementing evidence-based practices in teacher preparation programs in order to make effective educators for students with autism. The purpose of this study is to investigate to what extent teachers' performance is related to evidence-based practice.

\section{Research Questions}

The research aimed to answer three questions; one: What current evidence-based practices for teaching students with autism do teachers report using in the classroom? Two: What is the most common type of training that teachers have received to implement evidence-based practices? And three: What are teachers' knowledge and understanding of using evidence-based practices for teaching students with autism?

\section{Conceptual Framework}

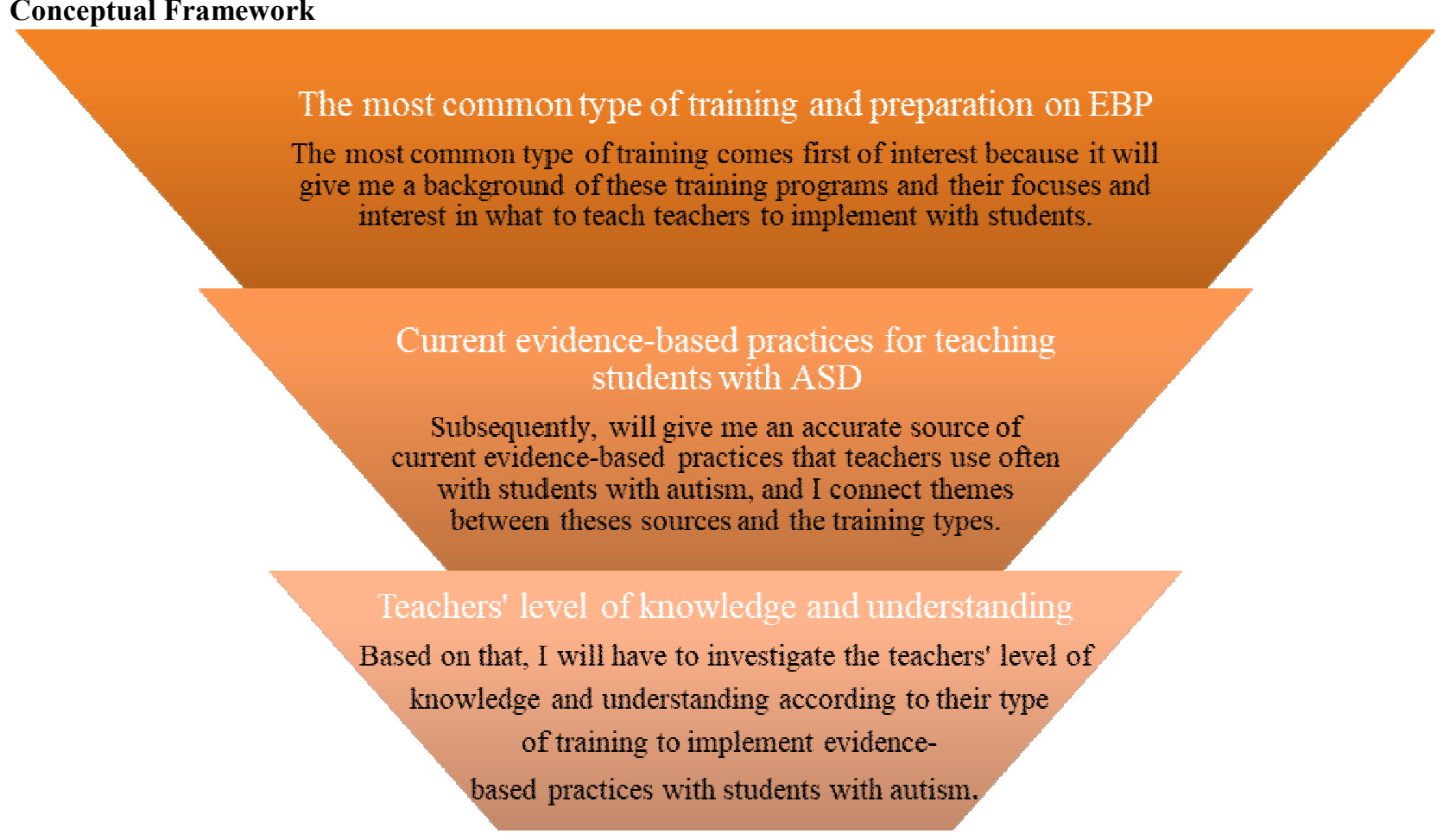

With the growing prevalence of autism spectrum disorders, a lot of useful interventions and practices have been established to teach and support students with autism (Stansberry \& Klingenberg, 2010). However, there is a concern that teachers and specialists are not able to implement practices that are effective. In 2007, the Office of Special Education Programs in the United States funded the National Professional Development Center on Autism Spectrum Disorders (NPDC). The primary goal of NPDC is to encourage the use of Evidence-Based 
Practices (EBPs) on infants, children, and youths with autism (Stansberry \& Klingenberg, 2010).

Regarding teachers' level of knowledge about how to teach children with ASD, Mostly teachers enhance their knowledge from such conferences and workshops which may not be enough for them to implement the strategies they have learned. For instance, when teachers attend a training conference to gain more knowledge, they receive an instructional manual (Bush, 1984; Cornett \& Knight, 2009). After the training, teachers are required to put into practice whatever they have learned of the evidence-based practices without receiving further time and instructions

Training the teachers typically received with length of time to implement changes is not enough to achieve full-level of fidelity to meet the needs of children with ASD (Bush, 1984; Cornett \& Knight, 2009). It is important that teachers understand how to select and implement evidence-based practices during their university preparation program. The contribution of this research is to bring more attention to training and implementing evidence-based practices in teacher preparation programs in order to make effective educators for students with autism. Marder and deBettencourt (2015) mentioned that higher education Institutions need to reform current coursework particular to ASD and measure if these courses offered with emphasize on EBPs.

\section{Research Methods}

The purpose of this study was to investigate to what extent teachers' perspective is related to evidence-based practice. The study's focus included the most prevalent practices, the common type of training on these practices, and teachers' knowledge and understanding of using these practices. The research also helped answer three questions; one: What current evidence-based practices for teaching students with autism do teachers report using in the classroom? Two: What is the most common type of training that teachers have received to implement evidence-based practices? And three: What are teachers' knowledge and understanding of using evidence-based practices for teaching students with autism?

Research Design. This study used mixed-method design to focus on measuring three things were identified in the literature, (a) the prevalence of evidence-based practices, (b) the most common type of training that teachers have received to implement these practices, (c) and teachers' knowledge and understanding of using evidence-based practices for teaching students with autism.

Participants. Criteria for eligibility to participate in this study included (a) employment as a teacher (male or female) of students with autism and (b) been in-service a duration 4 to 20 years and (c) holds a certification in special education. Potentially, three schools in Tampa had an access to the survey in order to gather a more comprehensive view of how evidence-based practices are acquired in undergraduate levels. This survey did not disseminate participants' names and contact information for confidentiality reasons.

Data Collection Instruments. After obtaining the (IRB) clearance, data were collected through an electronic survey instrument that disseminated three school in Tampa. Teachers of students with autism completed openended and Likert-type survey aligned to research questions and purpose.

The three-parts survey comprised of (1) the prevalence of evidence-based practices survey was developed specially for this study by (Qualtrics survey) tool to identify the most implemented practices in teaching learners with ASD. (2) Early Intervention Practices Scale was developed by Paynter et al., (2015) to evaluate the knowledge of practices. (3) Open-ended question were gathered from the participants on how the university programs supported them to build their knowledge to implement effective practices when teaching students with autism. Furthermore, the survey started with a set of basic demographic questions about age bracket, academic qualifications, district location, and time working with children with ASD. This data helped to measure the prevalence of using EBPs in the classroom, the type of training received to implement these practices and helps to measure teachers' knowledge of using EBPs.

Data Analysis. The first two research questions: What current evidence-based practices for teaching students with autism do teachers report using in the classroom? and (2) What is the most common type of training that teachers have received to implement evidence-based practices? Were investigated through survey part one which has three steps, (1) participants were asked to check strategies that they use from a list of the 27 EBPs identified by the National Professional Development Center (NPDC) on ASD. (2) If a participant checked on a strategy that he or she been using, they would be asked to check from next list of training type received to implement this strategy, for example (self-learning, pre-service preparation, in-service preparation, workshop, university course), and (3) the participant were asked to rate their use of each practice through 5-point Likert's scale ( 1 almost every day, 2 at least once a week, 3 once or twice a month, 4 rarely, 5 almost never). This last section of part one is a replication of the research of Burns and Ysseldyke (2009).

The second part of the survey is to investigate third research question: What teachers' knowledge and understanding of using evidence-based practices for teaching students with autism? to investigate this question, one section of the Early Intervention Practices Scale was developed by Paynter et al., (2015) was used. This scale is to evaluate participants' knowledge of each practice of the 27 EBPs on five-point scale that ranged from $1=$ Very little (Know nothing about this practice) to $5=$ To a very great extent (Know a great deal and could 
instruct others on this).

All scored points were exported to SPSS software (IBM Statistics). A descriptive analysis were conducted to provide information on the prevalence of EBPs and type of training were received by participants to implement these practices. The last part of the survey included open-ended questions about, first, whether participant believe that their undergraduate program has contributed to the growth of their skills to implement EBPs that was designed especially for students with ASD. Second, participants were asked to propose two recommendations regarding how their undergraduate program could have better prepared them to implement EBPs. Open coding was used to conduct and classify responses based on categories of recommendations.

Data for this last part were analyzed qualitatively to provide an in-depth understanding of the participants' experience (Snape \& Spencer, 2003). Open-ending question was coded according to the variety of participants' responses to the second part of the survey to reveal more comprehensive information that cannot be ascertained through only quantitative data (LaBarbera, 2017). When participants share their own perspectives about the research topic, they support a deeper understanding of the specific phenomenon (Snape \& Spencer, 2003).

\section{Result}

Data were exported from Qualtrics to a computer hard drive for coding and entry into the SPSS software for descriptive analysis. Descriptive analysis is presented below for the survey response data that is received. It contains a summary of the demographic profile of the respondents as well as the analysis of responses to questions related to the prevalence of evidence-based practices, the most common type of training, and participants' knowledge of each practices.

Ten teachers have participated in this study. The majority of the respondents who were special education teachers of students with autism were females with percentage of $90 \%$, and $10 \%$ were males. The number of years served as teachers of students with autism ranged from 1 to more than 20 years, with a mean of 2.20 (SD = 1.135) as shown in Table 1.

Table 1. demographic profile and the number of years served as teachers.

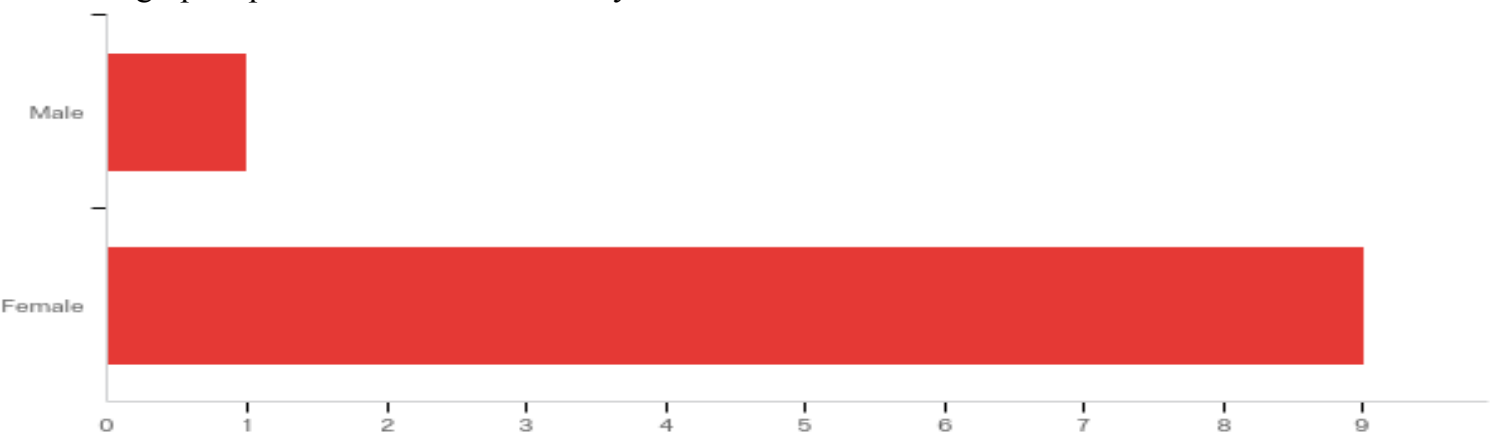

Numbers refers to the participants in table 1.

Years.

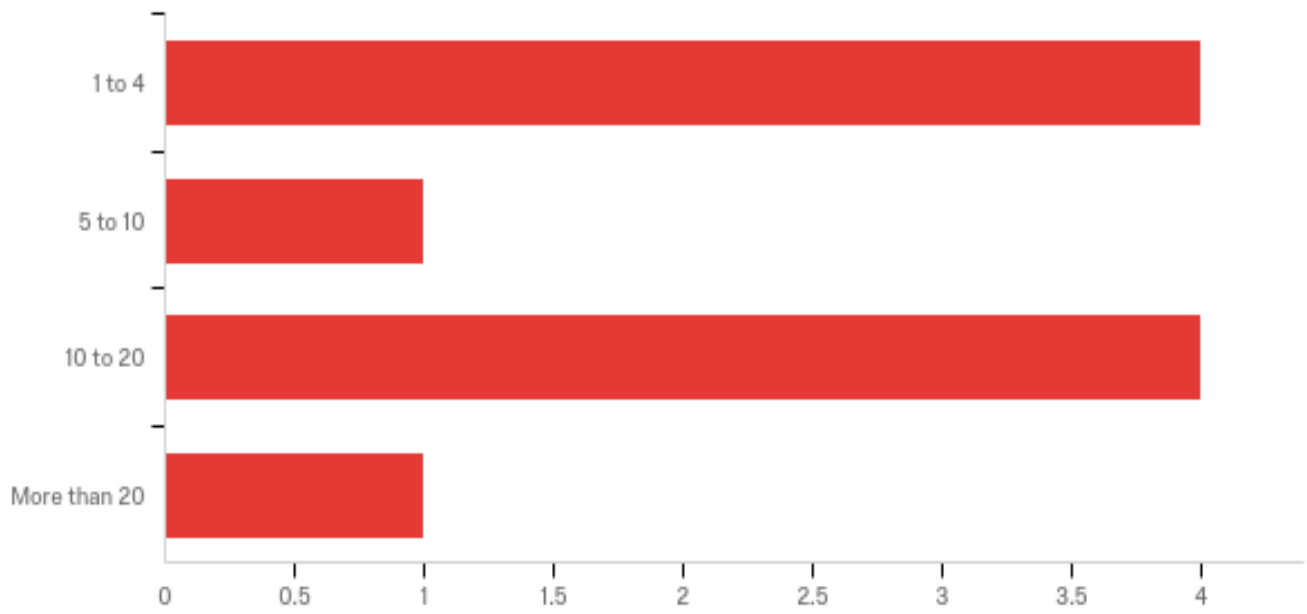

The prevalence of evidence-based practices.

The first research question inquired the reported of the prevalence and the frequency use of evidence-based practices using a 5-point Likert-type scale with almost every day, at least once a week, once or twice a month, 
three times a month, and almost never as the choices. $100 \%$ of the respondents indicated that the most common daily used practices are Functional Behavior Assessment (FBA) and Modeling (MD) almost every day.

As seen in Table 2. 100\% of the respondents indicated that they used Functional Behavior Assessment (FBA) and Modeling (MD) almost every day. Approximately 90\% of the respondents also reported a similar frequency for Time Delay (TD), and $80 \%$ for Visual Support (VS). Moreover, 30\% of the respondents indicated they used Task Analysis (TA) at least once week. The three least frequently reported practices were Picture Exchange Communication System (PECS), Video Modeling (VM), and Discrete Trial Teaching (DTT). 60\% of the respondents indicated they almost never used either (PECS) and (DTT). Moreover, 40\% of the respondents indicated the same frequency of use for Video Modeling (VM).

Table 2. The prevalence and the frequency use of evidence-based practices.

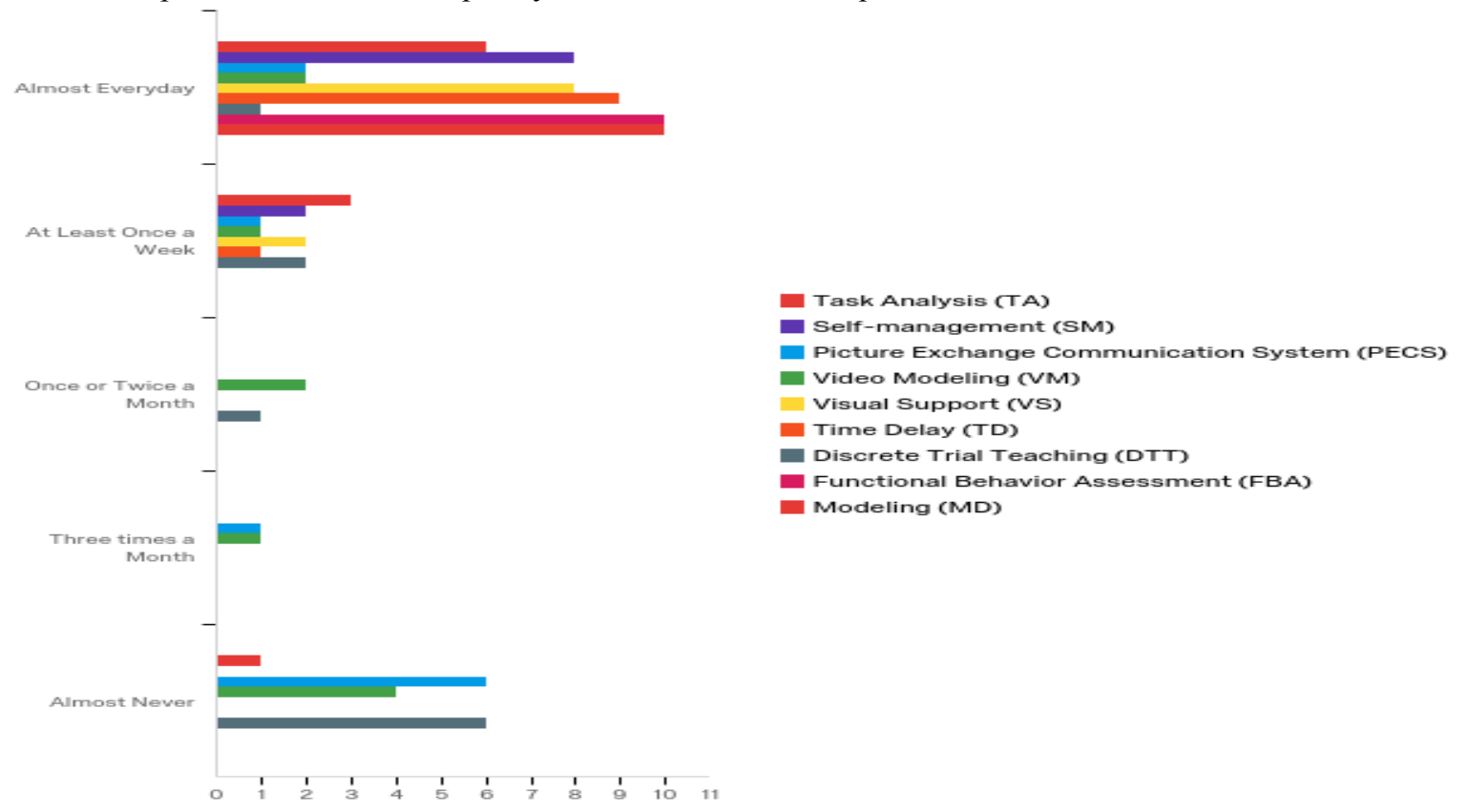

Numbers refers to the participants in table 2.

\section{The most common type of training}

The second research question inquired the reported of the most common type of training that teachers have received to implement evidence-based practices with students with autism. Participants were asked to indicate the type of training that thy received on these practices (TA, SM, PECS, VM, VS, TD, DTT, FBA, MD) from a list that most accurately reflects training types they received to implement this strategy. Which are, self- learning pre-service preparation, In-service preparation, workshop, and university course. As seen in Table 3, the statistics show that around $13.33 \%$ of the pre-service training was received on Visual Support (VS), Time Delay (TD) and Self-management (SM). Approximately $41.18 \%$ have received training on Functional Behavior Assessment (FBA) during job time. Also, job training was received on Visual Support (VS) with 26.67\% as well as $20.00 \%$ for Task Analysis (TA). Moreover, $40.00 \%$ of the respondents indicated they used self- learning to impalement self-management (SM) strategy, and 38.89\% used the same methods to impalement Modeling (MD). Statistics show that $70.00 \%$ of the participants indicated that thy never received a training on Time Delay (TD) and $25.00 \%$ have never received any type of training on Picture Exchange Communication System (PECS). All other comparisons were non-significant. 
Table 3. The most common type of training that teachers have received to implement evidence-based practices with students with autism. Numbers refers to the participants on the left of table 3 .

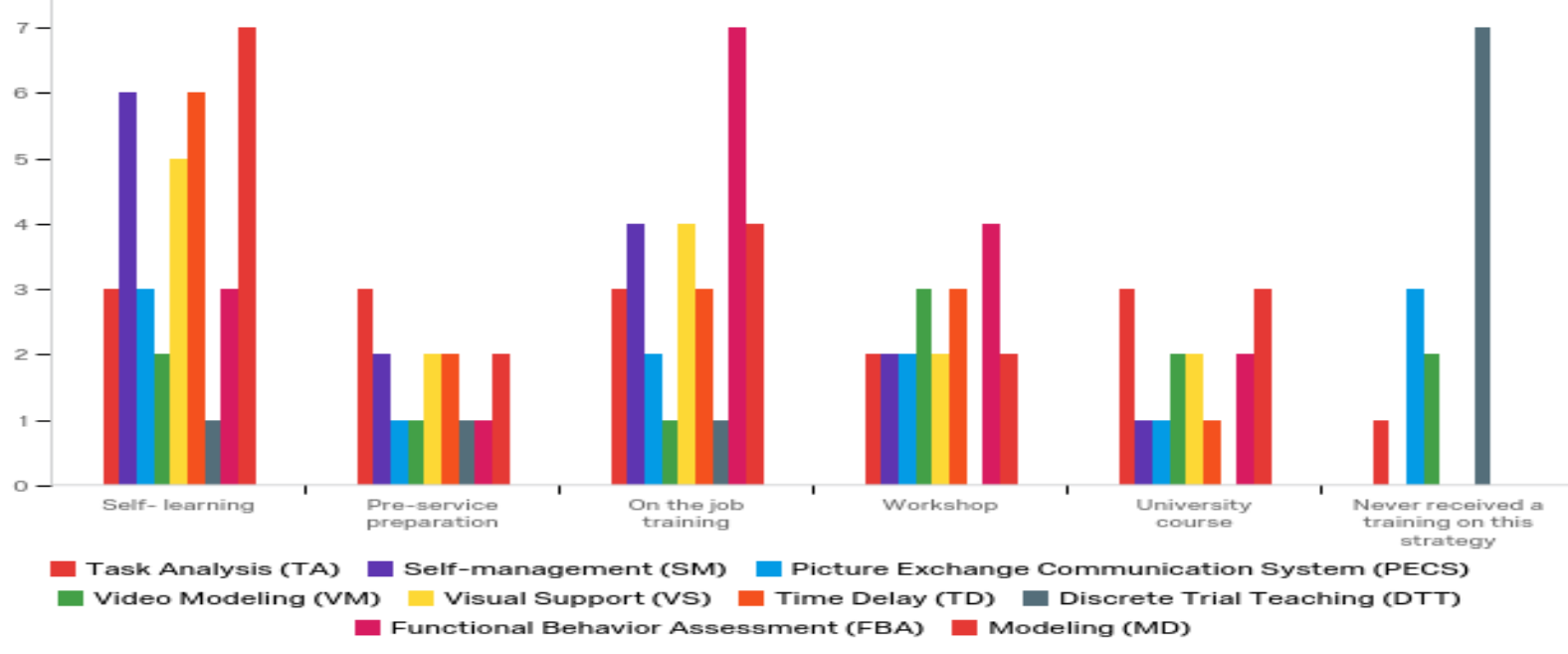

Knowledge of practices.

The third research question aimed to rate teachers' knowledge and understanding of each intervention practice from the list of the nine practices. Participants were asked to rate their knowledge of each practice on a fivepoint scale that ranged from $1=$ (Know nothing about this practice) to $5=$ (Know a great deal about this practice). Participants differed significantly in their knowledge of some category of practice. Contrasts revealed that participants reported being more knowledgeable about some practices with a mean of (in order of most to least): Modeling (MD) $(\mathrm{M}=4.40)$, Functional Behavior Assessment (FBA) $(\mathrm{M}=3.80)$ Self-management (SM) and Visual Support (VS) $(\mathrm{M}=3.70)$, Time Delay (TD) $(\mathrm{M}=3.60)$, Task Analysis (TA) $(\mathrm{M}=3.50)$, Video Modeling (VM) $(\mathrm{M}=3.30)$, Picture Exchange Communication System (PECS) $(\mathrm{M}=2.90)$, Discrete Trial Teaching (DTT) $(\mathrm{M}=2.10)$. All of these nine were from the EBPs category as seen in Table 4.

Table 4. Participants' knowledge of each practice on a five- point scale.

\begin{tabular}{|c|c|c|c|c|c|c|c|c|c|c|}
\hline & & $\begin{array}{c}\text { Task Analysis } \\
\text { (TA) }\end{array}$ & $\begin{array}{c}\text { Self- } \\
\text { management } \\
\text { (SM) }\end{array}$ & $\begin{array}{c}\text { Picture } \\
\text { Exchange } \\
\text { Communication } \\
\text { System (PECS) }\end{array}$ & $\begin{array}{l}\text { Video Modeling } \\
\text { (VM) }\end{array}$ & $\begin{array}{l}\text { Visual Support } \\
\text { (VS) }\end{array}$ & $\begin{array}{l}\text { Time Delay } \\
\text { (TD) }\end{array}$ & $\begin{array}{c}\text { Discrete Trial } \\
\text { Teaching (DT) }\end{array}$ & $\begin{array}{c}\text { Functional } \\
\text { Behavior } \\
\text { Assessment } \\
\text { (FBA) }\end{array}$ & Modeling (MD) \\
\hline \multirow[t]{2}{*}{$\mathrm{N}$} & Valid & 10 & 10 & 10 & 10 & 10 & 10 & 10 & 10 & 10 \\
\hline & Missing & 0 & 0 & 0 & 0 & 0 & 0 & 0 & 0 & 0 \\
\hline \multicolumn{2}{|c|}{ Mean } & 3.50 & 3.70 & 2.90 & 3.30 & 3.70 & 3.60 & 2.10 & 3.80 & 4.40 \\
\hline \multicolumn{2}{|c|}{ Std. Deviation } & 1.269 & .949 & 1.287 & 1.160 & .949 & 1.075 & 1.370 & 1.135 & .699 \\
\hline
\end{tabular}

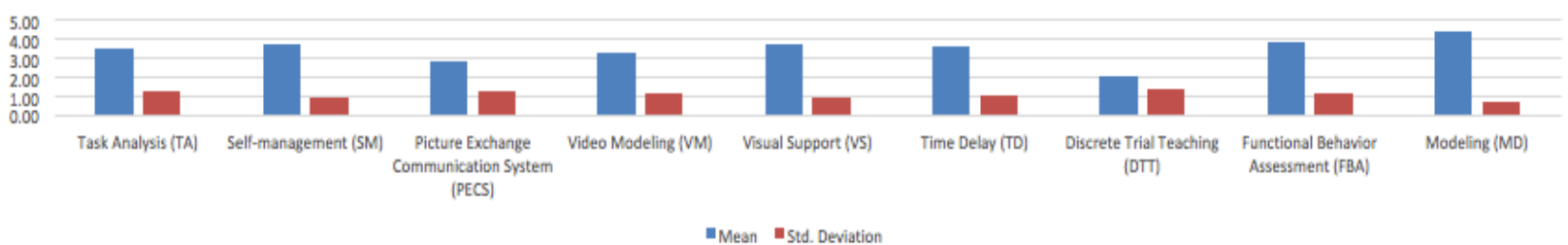

At the end of the survey, participants were asked an open-ending question to propose one recommendations regarding how their preparation program could have better prepared them to implement EBPs with students with autism. Total of 10 responses were collected from participants who served as teachers of students with autism ranged from 1 to more than 20 years' experience, with a mean of 2.20 ( $\mathrm{SD}=1.135)$. Open coding was conducted by classifying responses based on categories of recommendations. The qualitative data indicated that the highest number of respondents recommended more hands on training and examples of real life experience. In addition, more kind of job training that touched on autism-specific strategies was recommended. Lastly, several respondents asked for more in-depth and wide in-scope training specially at the beginning of their career as they were unfamiliar with some needed practices as seen in Table 5. 
Table 5. Open-ended responses from the teachers.

Please propose one recommendation regarding how your preparation program could have better prepared you to implement the evidence-based practices.

\begin{tabular}{|c|c|}
\hline Names & Quote \\
\hline Sara & $\begin{array}{l}\text { "This is my first year teaching in ESE, but I was a paraprofessional for the } 3 \text { years prior and I also } \\
\text { have a child on the spectrum. Both of these involved putting ideas into practice in the areas of } \\
\text { behavior, modeling and supports. One thing that would have helped me at the beginning of this school } \\
\text { year is to have a type of training that touched on the rest of these things just a little bit so I would at } \\
\text { least be familiar with them on a basic level. Things like data collection and how to go about it, PECS, } \\
\text { task analysis, and implementing lesson plans based on the access points. I have had to build all my } \\
\text { own lesson materials, some taken from gen ed, and tailor them to my special needs students. This is } \\
\text { difficult while being a first year teacher and while taking classes. I am very blessed that I have an } \\
\text { incredible ESE team at my school who are always willing to support me." }\end{array}$ \\
\hline Sofia & "By providing more in-depth and wide in-scope training." \\
\hline Adem & "On the job training, workshop" \\
\hline Camilla & "Support from those outside of the room whom have experience." \\
\hline Noha & "Continues training and examples." \\
\hline Jorden & "More hands on training and examples of real life experiences" \\
\hline & $\begin{array}{l}\text { "Educating pre-service teachers has probably expanded since I received my Masters degree in } 2004 \text { - } \\
\text { - that aside, I think more autism-specific classes would help. I understand that there is an } \\
\text { endorsement program now, which is beneficial. } \\
\text { My teacher preparation classes were so helpful to my teaching. I was given the "nuts and bolts" the } \\
\text { art and science of teaching and I was thankful for that knowledge. Now I started many years ago and } \\
\text { I feel that I learned more than what recent graduates of schools of education are receiving - personal } \\
\text { opinion, that may not pertain to all schools. I wish more beginning teachers had more training in } \\
\text { classroom management as related to ESE, a better understanding of the exceptionalities, learning } \\
\text { styles, and manifestations of disabilities." }\end{array}$ \\
\hline Emma & "By being more aware of how to teach ASD students effectively, since the beginning of my career." \\
\hline Isabella & on the job training and \\
\hline
\end{tabular}

\section{Discussion}

All of the 10 responding teachers with special education credentials remain working as special educators with students on the autism spectrum in different ages. The number of years served as teachers of students with autism ranged from 1 to more than 20 years, with a mean of $2.20(\mathrm{SD}=1.135)$ as shown in Table 1.

All participants stated on the survey and elaborated in one open-ended question, that their preparation program did not really contributed to their use of EBPs. Overall, the current results provide cause for concern and optimism. The first research question measured the prevalence of evidence-based practices that teachers use in their classroom.

Listed in Table 2 is the rank order of reported frequency of the most used practice from the list of 9 practices that were developed by the National Development Center on ASD. All of the respondents indicated that they used Functional Behavior Assessment (FBA) and Modeling (MD) almost every day. Approximately 9 of the respondents also reported a similar frequency for Time Delay (TD), and 8 for Visual Support (VS). The three least frequently reported practices were Picture Exchange Communication System (PECS), Video Modeling (VM), and Discrete Trial Teaching (DTT). 6 of the respondents indicated they almost never used either (PECS) and (DTT). Moreover, 30\% of the respondents indicated they used Task Analysis (TA) at least once week.

Ordinarily, teachers are more than willing to be effective if they were prepared with the appropriate service and curriculum. The second research question compared the practices that teachers are using and the most common type of training that teachers received to implement these practices. The most common type of training that they indicated most frequently on the survey that contributed to their use of evidence-based practices were received on the job training with $41.18 \%$ to implement Functional Behavior Assessment (FBA) and $40.00 \%$ of the respondents indicated they used self- learning to implement self-management (SM). Statistics show that $70.00 \%$ of the participants indicated that they never received a training on Time Delay (TD). Even though these three practices were used almost every day as teachers reported, however, teachers have acquired the skills to apply these practices either on the job training or self- learning. The result of this question indicated that there are some pre-service training and teacher preparation programs were unsuitable to meet all students needs because teachers are not well prepared with the necessary skills and understanding before starting the career.

Only $13.33 \%$ of the pre-service training was received on TD and Self-management SM. For the FBA as the most used practice, $30 \%$ of the teachers reported they have received pre-service training on the strategy, then 
again they had to do on the job training to implement FBA correctly. There was less attention given also to Visual Support (VS) and Self Management (SM) during their pre-service training programs, although these two practices were the most frequently used and ranged as almost every day. It seems pre-service training to certified special education teachers is focusing more on legal requirements and eligibility classification (Winn \& Blanton, 2005). Training courses do not focus on evidence-based practices that are helpful for students with autism (Holdheide \& Reschly, 2008). Those programs that certified our teachers who participated in this current study did not support them to implement and sustain their use of most EBPs.

In the survey, teachers were asked to make one recommendation regarding how their preparation programs could have better prepared them to implement EBPs with students with ASD. All 10 responses for this openended question were analyzed qualitatively. Open coding was conducted by classifying responses based on categories of recommendations. One main theme that emerged from the analysis of this data is the need to have more practical time in the pre-service programs on how to use more strategies in teaching students with ASD. The qualitative data also indicated that the highest number of respondents recommended training for implementing evidence-based practices (e.g., FBA, PECS, VS, DTT, etc.) and skills in the classroom. In addition, more kind of job training that touched on autism-specific strategies was recommended as seen in Table 5 . Goodall (2014) found that to increase teacher understanding of the spectrum they have to be subjected to lived experience examples, more practical access time in their preparation period is needed.

Seemingly the preparation programs need to provide frequent and quality hands-on experiences through providing more a clinical practice to ensure that teachers are well prepared to implement evidence-based practices that specially designed for students with ASD. As we saw from this current data, special education teachers need to receive their training prior to becoming certified, not after they start their career. For example, only $43 \%$ of the teachers received pre-service training on important practices that teachers use almost every day such are TD and FBA. In contrast, for the same tow practices, $70 \%$ of the teachers including the $43 \%$, have received on the job training again after they started their career. The continuous professional development purpose is to develop teachers' skills to keep up with the new practices, not to re-prepare teachers on the basics such as FBA and other strategies. The professional development responsibility is to bridge the research and practice gap.

More theoretical knowledge of how to implement EBPs with no practical path potentially resulting in difficulty to understand the practice and end up with no significant progress for the children and obstruct their learning development (Attwood, 2011; Bascom, 2012; De Clerc, 2011).

The third research question aimed to rate teachers' knowledge and understanding of each intervention practice from the list of the nine practices on a five-point scale that ranged from $1=$ (Know nothing about this practice) to $5=$ (Know a great deal about this practice). Overall, the findings showed that the highest means were $(M=4.40)$ for Modeling (MD) and FBA $(M=3.80)$, TD $(M=3.60), S M$ and VS $(M=3.70)$. Teachers earned knowledge in these practices by either self-learning or on the job training. The lowest mean was reported for Teaching (DTT) $(\mathrm{M}=2.10)$ and Picture Exchange Communication System (PECS) $(\mathrm{M}=2.90)$ as seen Table 4. Even though these practices are important in teaching communication and social skills for students with ASD, some evidence-based practices require more time and effort from teachers in order to implement them the way they were designed. Furthermore, teachers usually receive little instruction about these practices in their preparation programs (Bush, 1984; Cornett \& Knight, 2009).

\section{Limitations of the Study}

There were several limitations in this study. First, the low survey response rate, despite the intensity of recruitment effort, is a limitation. Even though this is a pilot study, the sample size limited the ability of generalization. This low response rate could be attributed to lack of desire on part of the of some school principals to participate in the study and disseminate the link of the survey to their teachers. Most of them never respond to the email.

Second, the scope of discussions. I don't have many years of experience of conducting researches and producing academic papers, the scope and depth of discussions in my paper is compromised in many levels compared to the works of experienced scholars. Third, at the end of the survey teachers were asked an openending question to propose one recommendation regarding how their preparation program could have better prepared them to implement EBPs with students with autism. I supposed to not force teachers to give only one recommendation and allow them to report three recommendations to have more in-depth data.

\section{Future Research}

Future research should focus on all training received as well as implementation of evidence based practices specially designed for ASD. The data presented demonstrate that there is room for improvement in the preparation programs of teachers working with students with ASD in how to implement EBPs. This improvement can be achieved by having more practice time for pre-service and using more strategies and current 
research in teaching student with ASD. From the data, teachers who received on the job training were able to demonstrate skills and knowledge in how to implement EBPs. The message to be derived from this finding is that teachers will be open to using evidence-based practices as long as they provided with the right type of preservice training. The format and content of preparation programs need to be evaluated more carefully, with data collected to know more about the practical path in these programs (Morrier, Hess, \& Heflin, 2011)

\section{References}

American Psychological Association. (2013). Diagnostic and statistical manual of mental disorder: DSM-5. Washington, D.C: American Psychological Association.

Attwood, T. (2011). The cognitive profile of children who have aspergers syndrome and the effects on the profile on daily living and the educational curriculum. Asia Pacific Autism Conference (APAC), Perth, 2011

Avramidis, E., Bayliss, P., \& Burden, R. (2000). A survey into mainstream teachers' attitudes towards the inclusion of children with special educational needs in the ordinary school in one local education authority. Educational Psychology, 20(2), 191-211.

Browder, D., Trela, K., \& Jimenez, B. (2007). Training teachers to follow a task analysis to engage middle school students with moderate and severe developmental disabilities in grade-appropriate literature. Focus on Autism and Other Developmental Disabilities, 22(4), $206-219$.

Burns, M.K., \& Ysseldyke, J.E. (2009). Reported prevalence of evidence-based instructional practices in special education. The Journal of Special Education, 43, 3-11.

Busby, R., Ingram, R., Bowron, R., Oliver, J., \& Lyons, B. (2012). Teaching elementary children with autism: Addressing teacher challenges and preparation needs. The Rural Educator, 33(2).

Bush, R. N. (1984). Effective staff development. San Francisco, CA: Far West Laboratory for Educational Research and Development.

Carrington, S. (1999). Inclusion needs a different school culture. International Journal of Inclusive Education, $3(3), 257-268$.

Center for Disease Control and Prevention, National Center on Birth Defects and Developmental Disabilities (2012). Prevalence of autism spectrum disorders - autism and developmental disabilities monitoring network, 14 Sites, United States, 2008. March, 2012.

Cornett, J., \& Knight, J. (2009). Research on coaching. In J. Knight (Ed.), Coaching: Approaches and perspectives (pp. 192-216). Corwin Press: Thousand Oaks, CA.

De Clerq, H. (2011). The pervasiveness of autism thinking in every aspect of daily life. Asia Pacific Autism Conference(APAC), Perth, 2011

Gable, R. A., Tonelson, S. W., Sheth, M., Wilson, C., \& Park, K. L. (2012). Importance, usage, and preparedness to implement evidence-based practices for students with emotional disabilities: A comparison of knowledge and skills of special education and general education teachers. Education and Treatment of Children, 35(4), 499-520.

Gersten, R., Fuchs, L. S., Compton, D., Coyne, M., Greenwood, C. R., \& Innocenti, M. S. (2005). Quality indicators for group experimental and quasi-experimental research in special education. Exceptional Children, 71, 149-164.

Goodall, E. e. (2014). Supporting teachers' Journeys towards full Inclusion of students on the autism spectrum in New Zealand. Journal of The International Association of Special Education, 15(2), 133-141.

Hall, L. J. (2015). Sustaining evidence-based practices by graduated special educators of students with ASD: Creating a community of practice. Teacher Education and Special Education, 38(1), 28-43.

Hastings, R., \& Oakford, S. (2003). Student teachers' attitudes towards the inclusion of students with special needs. Educational Psychology, 23, 87 - 94. Individuals With Disabilities Education Act, 20 U.S.C § 1400 (2014).

Hauber, J. A., Mehta, S. S., \& Combes, B. H. (2015). The Extent of Autism Knowledge of Novice Alternatively Certified Special Education Teachers in Texas. Journal of Special Education Apprenticeship, 4(2), n2.

Hess, K. L., Morrier, M. J., Heflin, L. J., \& Ivey, M. L. (2008). Autism treatment survey: Services received by children with autism spectrum disorders in public school classrooms. Journal of autism and developmental disorders, 38(5), 961-971.

LaBarbera, R. (2017). A Comparison of Teacher and Caregiver Perspectives of Collaboration in the Education of Students with Autism Spectrum Disorders. Teacher Education Quarterly, 44(3), 35.

Loiacono, V., \& Allen, B. (2008). Are Special Education Teachers Prepared to Teach the Increasing Number of Students Diagnosed with Autism?. International Journal of Special Education, 23(2), 120-127.

Marder, T. t., \& deBettencourt, L. U. (2012). Using a hybrid model to prepare special educators to teach students identified with ASD. Rural Special Education Quarterly, 31(3), 12-23.

Marder, T., \& deBettencourt, L. U. (2015). Teaching Students With ASD Using Evidence-Based Practices: Why Is Training Critical Now? 
Mohn, K. (2010). Autism in economics? A second opinion. Forum for Social Economics, 39(2), 191-208. doi: $10.1007 / \mathrm{s} 12143-008-9028-3$

Morrier, M., Hess, K. L., \& Heflin, L. J. (2011). Teacher training for implementation of teaching strategies for students with autism spectrum disorders. Teacher Education and Special Education, 34, 119-132.

Norwich, B. (2002). Education, inclusion and individual differences: Recognizing and resolving dilemmas. British Journal of Education Studies, 50(4), 482-502.

Odom, S. L., Boyd, B., Hall, L. J., \& Hume, K. (2010). Evaluation of comprehensive treatment models for individuals with autism spectrum disorders. Journal of Autism and Developmental Disabilities, 40, $425-437$.

Odom, S. L., Collet-Klingenberg, L., Rogers, S., \& Hatton, D. (2010). Evidence-based practices for children and youth with autism spectrum disorders. Preventing School Failure, 54, 275-282.

Paynter, J. M., \& Keen, D. (2015). Knowledge and use of intervention practices by community-based early intervention service providers. Journal of autism and developmental disorders, 45(6), 1614-1623. researchers (pp. 1-23).

Philips, S.C. (2005). Tahap Tahap Pengetahuan Mengenai Sindrom: Autisme Di Kalangan Guru Kelas Biasa.

Scheuermann, B., Webber, J., Boutot, A., \& Goodwin, M. (2003). Problems with personnel preparation in autism spectrum disorders. Focus on Autism and Other Developmental Disabilities, 18, 197-206.

Schindler, H. R., \& Horner, R. H. (2005). Generalized reduction of problem behavior of young children with autism: Building trans-situational interventions. American Journal on Mental Retardation, 110(1),

Scull, J., \& Winkler, A. M. (2011). Shifting trends in special education. Washington, DC: Thomas B. Fordham Institute.

Simpson, R. L., de Boer-Ott, S. R., \& Smith-Myles, B. (2003). Inclusion of learners with autism spectrum disorders in general education settings. Topics in Language Disorders, 23, 116-133.

Snape, D., \& Spencer, L. (2003). The foundations of qualitative research. In J. Ritchie \& J.Lewis (Eds.), Qualitative research practice: A guide for social science students and

Stahmer, A. C., Collings, N. M., \& Palinkas, L. A. (2005). Early intervention practices for children with autism: Descriptions from com- munity providers. Focus on Autism and Other Developmental Disabilities, 20, 6679.

Stahmer, A. C., Rieth, S., Lee, E., Reisinger, E. M., Mandell, D. S., \& Connell, J. E. (2015). Training teachers to use evidence-based practices for autism: Examining procedural implementation fidelity. Psychology In The Schools, 52(2), 181-195. doi:10.1002/pits.21815

Stansberry-Brusnahan, L. L., \& Collet-Klingenberg, L. L. (2010). Evidence-based practices for young children with autism spectrum disorders: Guidelines and recommendations from the National Resource Council and National Professional Development Center on Autism Spectrum Disorders. International Journal of Early Childhood Special Education, 2(1).

Suhrheinrich, J., Dickson, K. S., Rieth, S. R., Lau, A. F., \& Stahmer, A. C. (2016). Exploring the relationship between classroom type and teacher intervention fidelity. International Electronic Journal of Elementary Education, 9 (2SpecialIssue).

Toran, H. h., Westover, J. j., Sazlina, K. s., Suziyani, M. s., \& Hanafi, M. m. (2016). The preparation, knowledge and self-reported competency of special education teachers regarding students with autism. Pertanika Journal Of Social Sciences \& Humanities, 24(1), 185-196.

Wong, C., Odom, S. L., Hume, K. A., Cox, A. W., Fettig, A., Kucharczyk, S., Brock, M.E., Plavnick, J. B., Fleury, V. P., \& Schultz, T. R. (2015). Evidence-based practices for children, youth, and young adults with autism spectrum disorder: A comprehensive review. Journal of Autism and Developmental Disorders, 45, 1951-1966. 